einstein

Official Publication of the Instituto Israelita de Ensino e Pesquisa Albert Einstein

ISSN: 1679-4508 | e-ISSN: 2317-6385

\title{
Spontaneous subepithelial hemorrhage: the Antopol-Goldman lesion
}

\section{Hemorragia subepitelial espontânea: lesão de Antopol-Goldman}

Eduardo Kaiser Ururahy Nunes Fonseca', Roberto Vitor Almeida Torres', Luiz Raphael Pereira Donoso Scoppetta', Cesar Higa Nomura'

${ }^{1}$ Instituto do Coração, Hospital das Clínicas, Faculdade de Medicina, Universidade de São Paulo, São Paulo, SP, Brazil.

DOI: 10.31744/einstein_journal/2021AI5829
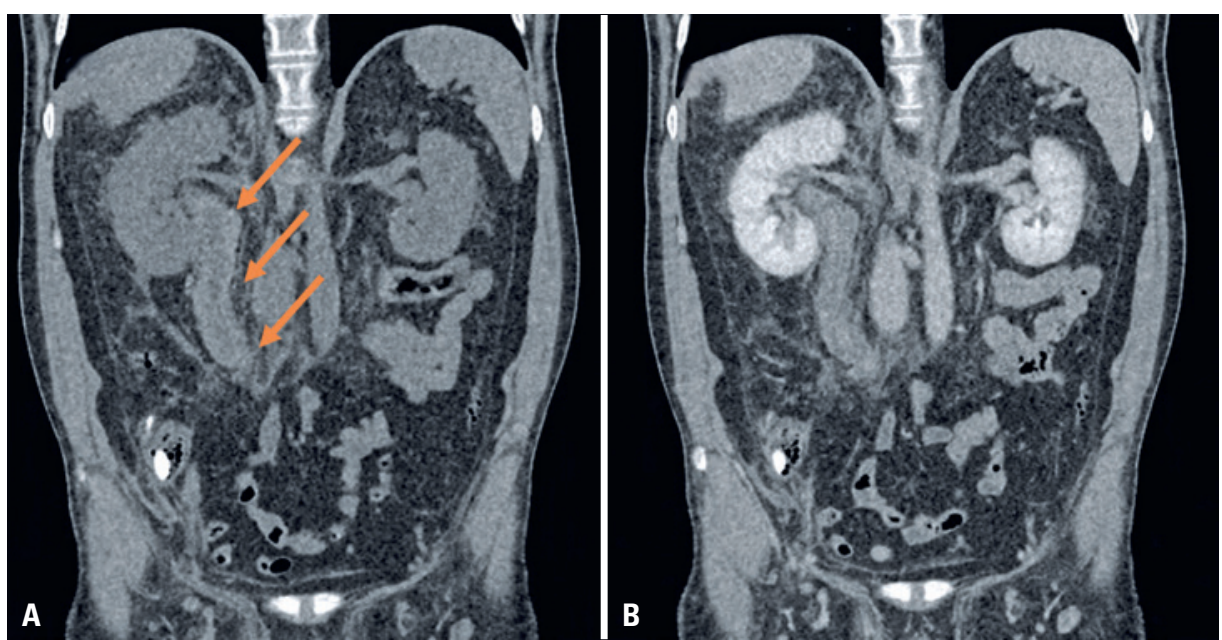

Figure 1. Abdominal computed tomography in coronal view. (A) unenhanced image shows a hyperattenuating circumferential thickening of the right ureter wall in practically its entire extension with adjacent fat-stranding; (B) contrast-enhanced image shows no enhancement of the ureteral wall. These findings are compatible with an intramural hematoma. It should be highlighted that given the hyperattenuation of the subepithelial hematoma, it should be mistaken by a diffuse enhancement of the ureteral wall if the non-contrast phase is not performed

Fonseca EK, Torres RV, Scopetta LR, Nomura $\mathrm{CH}$. Spontaneous subepithelial hemorrhage: the Antopol-Goldman lesion. einstein (São Paulo). 2021; 19:eAl5829.

\section{Corresponding author:}

Eduardo Kaiser Ururahy Nunes Fonseca Avenida Dr. Enéas Carvalho de Aguiar, 44 Cerqueira César

Zip code: 05403-900 - São Paulo, SP, Brazil

Phone: (55 11) 2661-5000

E-mail: eduardo.kaiser@incor.usp.br

\section{Received on:}

May 6, 2020

\section{Accepted on:}

Oct 29, 2020

\section{Copyright 2021}

\section{(c) By}

This content is licensed

under a Creative Commons

Attribution 4.0 International License.

A 55-year-old man admitted to our emergency department complaining of right flank acute pain. He also referred epistaxis, gingival bleeding, and hematuria for the past 3 days. His physical exam demonstrated abdominal subcutaneous hematomas and he referred abdominal tenderness on palpation. Seven days before these symptoms, his daily warfarin dose has been increased. His blood tests showed that the International Normalized Ratio was markedly elevated (3.6; his previous exam from before dosage increase was 2.2).

An abdominal computed tomography was requested (Figure 1) and showed hyperattenuating and non-enhancing circumferential thickening of the right ureter wall, compatible with extensive parietal hematoma.

Spontaneous subepithelial hemorrhage is a rare cause of abdominal pain and hematuria ${ }^{(1-3)}$ and this is usually associated with bleeding diathesis, 
mostly from anticoagulant therapy, as seen in our case. This bleeding is also called "Antopol-Goldman lesion" after the first description of this entity. Unenhanced abdominal computed tomography is of great help for this difficult diagnosis as it reveals a spontaneously hyperattenuating ${ }^{(1,4-6)}$ thickening of the renal pelvis and/or ureteral wall. This finding may be difficult to differentiate from contrast enhancement in contrastenhanced images, making unenhanced phases a must for this diagnosis.

Both urologists and radiologists should be aware of this benign as it may mimic urothelial neoplasms and lead to unnecessary nephrectomy, approximately $30 \%$ in the first description. ${ }^{(3)}$ Emergency radiologists must maintain a high grade of suspicion, primarily in patients using anti-coagulants as this diagnosis is rarely suspected before image. ${ }^{(1-6)}$ Spontaneous subepithelial hemorrhage normally resolve spontaneously after anticoagulants discontinuation and its association with hydronephrosis or urinary obstruction is rare. ${ }^{(1)}$

\section{AUTHORS' INFORMATION}

Fonseca EK: http://orcid.org/0000-0002-0233-0041

Torres RV: http://orcid.org/0000-0001-5547-6821

Scoppetta LR: http://orcid.org/0000-0002-6678-4034

Nomura CH: http://orcid.org/0000-0002-7131-6614

\section{REFERENCES}

1. Gayer G, Desser TS, Hertz M, Osadchy A, Daniel BL, Zissin R. Spontaneous suburothelial hemorrhage in coagulopathic patients: CT diagnosis. AJR Am J Roentgenol. 2011;197(5):W887-90.

2. Eccher $A$, Brunelli $M$, Gobbo $S$, Ghimenton $C$, Grosso G, lannucci $A$, et al. Subepithelial pelvic hematoma (Antopol--Goldman lesion) simulating renal neoplasm: report of a case and review of the literature. Int J Surg Pathol. 2009;17(3):264-7. Review.

3. Antopol W, Goldman L. Subepithelial hemorrhage of renal pelvis simulating neoplasm. Urol Cutaneous Rev. 1948;52(4):189-95.

4. Kossol JM, Patel SK. Suburothelial hemorrhage: the value of preinfusion computed tomography. J Comput Assist Tomogr. 1986;10(1):157-8.

5. Phinney A, Hanson J, Talner LB. Diagnosis of renal pelvis subepithelial hemorrhage using unenhanced helical CT. AJR Am J Roentgenol. 2000; 174(4):1023-4

6. Danaci M, Kesici GE, Kesici H, Polat C, Belet U. Coumadin-induced renal and retroperitoneal hemorrhage. Ren Fail. 2006;28(2):129-32. 